\title{
Un deseo frustrado: la hegemonía (o el descon- cierto de la crítica ante los autores del 2000 a lo largo de la primera década del siglo XxI)*
}

\author{
Ana Rodríguez Callealta \\ Universidad de Alcalá
}

\begin{abstract}
Los autores del 2000, nacidos a partir de 1969, se constituyen como una generación sin centro: ni antagonismos ni tendencias dominantes. Así, esta promoción no-rupturista, rompe con la dinámica histórica y sistemática de las hegemonías, inaugurando una nueva etapa caracterizada por la diversidad y la convivencia no conflictiva de opciones. Todo lo cual provocará un sintomático desconcierto entre la crítica literaria. Al análisis de algunas de las problemáticas que la gestación del relato generacional del 2000 ha encontrado a lo largo de la primera década del siglo xxI está dedicado este artículo.
\end{abstract}

Keywords: Poesía española, autores del 200o, diversidad, relato generacional, crítica literaria.

En las últimas décadas, el método generacional ha sido puesto entredicho por numerosos estudiosos desde diferentes enclaves teóricos. Sin embargo, tal y como constata Ángel L. Prieto de Paula, este «viene funcionando instrumentalmente sin grandes problemas»; de modo que, más allá «de la dispersión de posiciones teóricas, lo caracteriza su procedimiento de aplicación práctica $»^{2}$. Por ello, cuando nos acercamos a la crítica de poesía española reciente -específicamente a aquella que se desarrolla a lo largo de la primera década del siglo xxI- conviene asumir la existencia de generaciones en aquello que, vagamente, podríamos llamar el «inconsciente crítico», con la consiguiente delimitación por tramos de edad ${ }^{3}$. Ello nos permite contemplar la creación crítica de los denominados «relatos generacionales». $\mathrm{Al}$ respecto, Miguel Casado ha dilucidado dos fases en este desarrollo. Una primera, denominada delimitadora, en la cual «se propone el establecimiento

\footnotetext{
* El presente trabajo se comprende en el marco de la Tesis Doctoral sobre «Poesía femenina española. Última década del siglo xx y primera década del siglo xxI», que en la actualidad se encuentra en proceso gracias a una Ayuda para la Formación del Personal Investigador del Programa Propio de la Universidad de Alcalá.

I Ángel L. Prieto de Paula, «Poesía en la era de la perplejidad», Las moradas del verbo. Poetas españoles de la democracia, Madrid, Calambur, 2010, p. I2.

2 Miguel Casado, Los artículos de la polémica y otros textos de poesía, Madrid, Biblioteca Nueva, 2005, p. 32.

3 Siguiendo esta lógica, utilizaremos los umbrales de nacimiento asociados al método generacional desde una perspectiva instrumental. Si la generación del 80 engloba poetas nacidos entre 1954 y I968, la del 2000 comienza en 1969 y se extiende hasta 1983.
} 
de la lista canónica de los autores que constituyen una generación», generalmente a través de la publicación de una «antología acompañada de un prólogo esquemático» 4 . A esta le seguiría una segunda fase simplificadora en la que «se propone no ya la selección de nombres, sino el diseño de la tendencia estética dominante en el grupo generacional» ${ }^{5}$ :

[...] junto a la fijación a través de antologías de una nómina o canon de poetas, tarea por fuerza arbitraria y polémica, el método vigente propone un relato generacional, es decir, un entramado teórico que pretende establecer, no solo la existencia de una generación, sino sobre todo los rasgos que constituyen su estética dominante y el proceso seguido por ella a través del tiempo ${ }^{6}$.

El objeto de este artículo es el análisis de algunas de las problemáticas que el relato generacional del 2000 ha encontrado a su paso; problemáticas que, tal y como veremos, se deben a la dificultad de su «simplificación».

Desde que en 1994 Andrés Sánchez Robayna publicase Paradiso, la presencia en las antologías de los jóvenes autores del 2000 comienza a ser cada vez más frecuente hasta desembocar en el último lustro de la primera década del siglo XXI, cuando prácticamente todas las selecciones de poesía actual los incluyen. Estas primeras apariciones esporádicas -intensificadas a partir de 1997- tienen lugar en un momento en que en el panorama comienzan a sentirse los primeros síntomas de una diversidad que en años posteriores se constituirá como rasgo esencial. Tras una década marcada por la oposición entre la vertiente figurativa -que había ostentado la hegemonía entre I985 y I9957 - y la no-figurativa; la promoción de los 80 entra en una tercera fase dominada por la recuperación de las estéticas anteriormente sumergidas en el relato central de la generación y el desmantelamiento y posterior desintegración de las dicotomías ${ }^{8}$. En este contexto surge como corriente la "poesía de la conciencia», antologada parcialmente en Feroces (I998) e impulsada con los sucesivos encuentros de Voces del Extremo, inaugurados en 1999 ${ }^{9}$. Son estos unos años de transición en los que cobra protagonismo el último tramo de la generación del 80 a la vez que empiezan a publicar sus

\footnotetext{
4 Miguel Casado, op. cit., p. 32.

5 Miguel Casado, op. cit., p. 33.

6 Miguel Casado, op. cit., p. 53.

7 Luis Antonio de Villena, «Inflexiones a la voz órfica», La lógica de Orfeo (Antología), Madrid, Visor, 2003, p. 18.

8 Juan José Lanz estudia los dos primeros momentos generacionales, señalando la apertura de «un nuevo período en el desarrollo generacional» a principios de los 90. «Notas para una periodización. En torno a las antologías y el canon poético (1977-1997)», La poesía durante la Transición y la generación de la Democracia, Madrid, Devenir, 2007, pp. I8I-2I8 (citado: p. 205). 9 Alberto García-Teresa, Poesía de la conciencia crítica (1987-20II), Madrid, Tierradenadie Ediciones, 2013.
} 
primeras entregas algunas voces de la siguiente. Ya en I999 José Luis García Martín trató de señalar el relevo generacional con La generación del 99. Pero, tal y como también advertirá Villena, esta se publica en una fecha temprana. Sin embargo, el diálogo que la misma establecía con las anteriores del crítico -especialmente Selección nacional (1995)- resultaba verdaderamente significativo, por cuanto transparentaba la sensación de estar en un momento todavía informe, pero distinto ${ }^{\mathrm{IO}}$. Asistimos, en definitiva, a un clima de relativa apertura en el que algunas antologías muestran ya una mayor amplitud de miras («Última fila. Estudio-antología sobre poesía del 90» de José Luis Morante, 1997), mientras que otras de talante retrospectivo anuncian el fin de una etapa (Poesía española reciente (I980-200o) de Juan Cano Ballesta, 200I).

A diferencia de lo sucedido a lo largo de todo el siglo xx, estos autores se constituyen como una generación sin centro, rompiendo con la dinámica histórica de las hegemonías. Debido a ello, esta generación estará ligada a lo largo de toda la primera década del siglo Xxi a un relato generacional lleno de claroscuros. La falta de una tendencia dominante opuesta a la estética nuclear de sus predecesores unida al carácter silencioso de su irrupción provocará un desconcierto entre la crítica literaria, acostumbrada a «una música concreta» ${ }^{\mathrm{II}}$. Esta promoción no cuenta en sus inicios con una antología clave que ancle su lugar en el panorama y consolide el relevo generacional. Así, su presentación en sociedad tendrá lugar a través de una serie antologías publicadas entre el 2000 y el 2004 en las que, de forma conjunta, se irá construyendo un relato generacional propio vertebrado por la ruptura del paradigma crítico hasta entonces vigente. Algunos de los síntomas visibles en el último cuatrienio de la década anterior (superación de las dicotomías, apertura, etc.), cristalizan ahora en la emergencia de un grupo de poetas que por primera vez se organiza en torno a la diversidad ${ }^{12}$. La primera antología que esboza los nuevos parámetros de recepción es «Pasar la página. Poetas para el nuevo milenio», publicada por Manuel Rico en el año 200o. Al igual que en otras posteriores, la función crítica de la antología se orienta hacia la «delimitación» de un nuevo «territorio»². Aunque en la nómina se inclu-

Io Luis Antonio de Villena, «La inteligencia y el hacha (Un panorama de la Generación poética de 2000", La inteligencia y el hacha (Un panorama de la Generación poética de 200o), Madrid, Visor, 20I0, pp. I6-I7.

II Alberto Santamaría, «Nuevos territorios poéticos. Apuntes para una lectura abierta de la joven poesía española», El maquinista de la generación, II, 2006, p. 98.

I2 Se trata, tal y como anota José Andújar Almansa, de un momento único «en que el pluralismo y la diversidad de tendencias estéticas coexisten en perfecta disparidad y alternancia» («Retrato robot de la poesía reciente», Paraíso, 2, 2007, p. 24).

I3 Nuestra concepción de las antologías se apoya en los presupuestos de Alfonso García Morales, quien considera que estas parten siempre de una «conciencia crítica y/o histórica» que cuando «es explícita (vimos que no es imprescindible) suele hacerlo en los preliminares»; 
yesen, como será habitual, autores de dos generaciones, los planteamientos esbozados subrayaban la emergencia de una nueva promoción. Con la intención de señalar el fin de una etapa, la selección aglutinaba un conjunto plural de autores diferenciado de las promociones precedentes y caracterizado por la superación de las dicotomías, la aprehensión libre de la tradición heredada y la ampliación de referentes:

Contra lo ocurrido en etapas anteriores de nuestra historia literaria, no hay -o sólo parcialmente- una reacción colectiva en contra de la poética hegemónica protagonizada por sus predecesores [...] desde la trinchera de una estética alternativa. Sí hay sin embargo una actitud beligerante en favor de la diversidad ${ }^{14}$.

Un año más tarde, Josep M. Rodríguez edita Yo es otro. Autorretratos de la nueva poesía (200I) con el fin de ofrecer «una visión relativamente amplia de esta nueva promoción de poetas» ${ }^{15}$. En esta ocasión, la inclusión de autores nacidos a partir de 1965 -pertenecientes, por tanto, al último tramo de la generación del 80- continúa la propuesta de Villena en Io menos 30 (I997) ${ }^{16}$. Ello subraya la proyección de los últimos años del siglo en la nueva generación, enfatizando la visión de ambos contextos como un todo más amplio. En cuanto a los parámetros de recepción esbozados por el antólogo, estos inciden en la pluralidad, la convivencia no conflictiva de opciones, la ausencia de proclamas generacionales y la superación de las dicotomías, «como si en su voluntad de diálogo no quisiera creerse determinados enfrentamientos estéticos, como los dirimidos en la generación anterior entre 'poesía del silencio' y “poesía de la experiencia'»”. En esta línea, Inéditos. II poetas (2002) y Periféricos. I5 poetas (2004), ambas de Ignacio Elguero, junto con Veinticinco

interviniendo de esta manera en la creación de «categorías con las que abarcar, entender y clasificar la literatura» («Introducción. Función canonizadora y estructura intertextual de la antología poética», Los museos de la poesía. Antologías poéticas modernas en español (I892-I94I), Sevilla, Ediciones Alfar, 2008, pp. 13-40; citado: p. 25, 29, 28). Asimismo, nos hacemos eco de la propuesta de Marie Estripeaut-Bourjac, para quien el prólogo de una antología «adopte en effet le rôle de 'délimitation, d'un territoire'» («Le prologue comme délimitation du territoire de l'anthologie», Geniève Champeau y Nadine Ly (coords.), Le phénomène anthologique dans le monde ibérique contemporain, Bourdeaux, Maison des Pays Ibériques, 2000, p. I04). Finalmente, una introducción a la tipología antológica puede verse en Francisco Ruiz Casanova, «Tipología de las antologías poéticas», Anthologos. Poética de la antología poética, Madrid, Cátedra, 2007, pp. II9-I39. Nosotros tomamos su diferenciación básica entre «programáticas» y «panorámicas», aunque con algunas matizaciones.

I4 Manuel Rico, «Pasar la página. Poetas para el nuevo milenio», Diálogo de la lengua, 4-5, 2000, p. I6.

I5 Josep M. Rodríguez, «Presentación», Yo es otro. Autorretratos de la nueva poesía, Barcelona, DVD Ediciones, 200I, p. II.

I6 Josep M. Rodríguez, op. cit., p. I2.

17 Josep M. Rodríguez, op. cit., p. I4. 
poetas españoles jóvenes (2003), en selección de Ariadna G. García, Guillermo López Gallego y Álvaro Tato, contribuirán igualmente a vincular a los jóvenes autores con una nueva actitud. No obstante, frente a la fuerza del discurso antológico relativo a la generación del 8o, estas antologías perfilan un nuevo enclave desde un aparato crítico sustancialmente más débil y menos trabado. Tanto la existencia de una oposición frontal entre la estética figurativa y la novísima como la extensión de este enfrentamiento a otros sectores dentro de la misma promoción, dieron lugar en la década de los 90 a una dinámica antológica fuerte marcada por la necesidad de reivindicar determinados sectores dentro del panorama. A pesar del tono beligerante que de ello se derivaba, la oposición real entre estéticas propició la existencia de antologías que excedían la mera ejemplificación, inmiscuyéndose en el territorio de la crítica literaria periodística ${ }^{18}$. Todo lo cual nos permite reconstruir el mapa del periodo en función de los distintos espacios delimitados por aquellas ${ }^{19}$. Sin embargo, conforme comienzan a apagarse los enfrentamientos, la funcionalidad crítica de la antología se diluye también. Desde esta perspectiva, las recopilaciones que dan a conocer a los más jóvenes forman parte de este proceso gradual de desintegración. Se trata de discursos que señalan el relevo generacional relacionando a estos poetas con unos parámetros específicos de recepción que atañen más a la ruptura del paradigma crítico y a la relación no conflictiva entre estéticas y con respecto a la generación anterior, que a la delimitación de opciones poéticas ${ }^{20}$. Una consecuencia, en definitiva, tanto de la mitigación de los enfrentamientos como de la propia constitución de la generación del 2000 en tanto que formación diversa; sobre todo si se tiene en cuenta que la existencia de corrientes dominantes cataliza de algún modo la creación de categorías.

La lógica de Orfeo, publicada por Villena en 2003, ejemplifica el desconcierto de la crítica ante esta promoción y la sensación difusa con la que es percibida. Tanto por la fecha de publicación como por los presupuestos planteados, esta se alinea con aquellas que presentan a la nueva generación. De hecho, el prólogo traza algunos de los rasgos fundamentales del relato generacional (en este sentido, la superación de las dicotomías que funciona como el fundamento básico de la antología constituye el soporte de

I8 Véase nota 13. Al respecto, Ruiz Casanova ha documentado cómo los críticos se sienten en este momento suplantados por los antólogos (Anthologos..., op. cit., p. 203).

I9 Una aproximación puede verse en Ana Rodríguez Callealta, «Reflexiones en torno a las antologías poéticas finiseculares», Puentes de crítica literaria y cultural, 6, 2016, pp. 75-77. También Marta Beatriz Ferrari ha analizado el panorama antológico del momento refiriéndose a tres «alineaciones»: experiencia, diferencia y conciencia («Un error necesario: sobre las antologías poéticas españolas de la década de los 90», en Laura Scarano (ed.), Los usos del poema: poéticas españolas últimas, Granada, Diputación, 2008, pp. 27-44).

20 No así en los casos de «Pasar la página», de Manuel Rico (2000) y La lógica de Orfeo de Luis Antonio de Villena (2003). 
la actitud aperturista que motiva todas aquellas características que le son propias). Aunque la nómina conjugara a autores de dos promociones, Villena establecía una escisión clara entre los poetas del 80 (precedentes) y el conjunto antologado (sucesores), al cual atribuía una postura radicalmente distinta de la de aquellos;

un cambio muy relevante con lo que ocurría en la generación anterior. Estos poetas nuevos (o más nuevos) no parecen querer plantear la poesía como un campo de batalla estilístico, pleno de irreconciliables enemigos y de concepciones antagónicas -a muerte-de la palabra poética ${ }^{21}$.

Ahora que, pese a la nitidez con la que atisba la existencia de esta nueva promoción, en otros puntos muestra una actitud dubitativa que contrasta significativamente con el talante decidido de sus entregas anteriores. En este sentido, es llamativo el hecho de que niegue el relevo generacional que, en cierto modo, él mismo está contribuyendo a consolidar: «La llamada Generación del 80 (que aunque, cronológicamente tiene ya otra detrás y actuante, pero aún no ha sido oficialmente sustituida como generación joven, quizá por la aparente falta de ruptura) $[. .].\rangle^{22}$.

Otras aportaciones de diversa índole irán pautando las coordenadas esenciales de la nueva promoción a lo largo de esta primera década del siglo XXI. En esta línea, «Apuntes sobre el puente» de Andrés Neuman (2005) puede leerse como una auténtica declaración de principios en la que se condensan los ejes en torno a los cuales se construye el relato generacional. El autor recurre a la imagen del puente para «ilustrar la situación de una generación [...] que en buena parte ha crecido sintiéndose híbrida, admirando estéticas distintas y resistiéndose a elegir $»^{23}$. De modo que «uno deja de ver dicotomías donde hay paralelismos» ${ }^{24}$. Con todo, la construcción conjunta de este relato generacional encuentra a su paso algunos claroscuros y complicaciones. Así, la adhesión de los más jóvenes a la generación anterior o a su último tramo se mantiene en algunas aportaciones críticas, hasta el punto de que Luis Bagué, siguiendo a Andújar Almansa, considere todavía en 2012 que «Lo que se conoce como generación de 2000 es, en realidad, un hiperónimo que acoge la continuidad de dos tramos generacionales ${ }^{25}$. Este aserto, que contiene en sí mismo una contradicción derivada de la diferenciación

2I Luis Antonio de Villena, «Inflexiones a la voz órfica», La lógica de Orfeo, Madrid, Visor, 2003, p. 29.

22 Luis Antonio de Villena, op. cit., p. 15.

23 Andrés Neuman, «Apuntes sobre el puente», Clarín: revista de nueva literatura, 59, 2005, p.

22.

24 Ibid.

25 Luis Bagué, «Introducción», Quien lo probó lo sabe: 36 poetas para el tercer milenio, Zaragoza, Institución «Fernando el Católico», 2012 p. I7. 
y posterior ensamblaje, se relaciona con una cuestión sumamente interesante. Si se piensa de qué manera el continuismo y la pluralidad iniciales darán paso a la posterior dominancia de una vertiente sobre las restantes ${ }^{26}$; el puente trazado entre los jóvenes del 2000 y los poetas del último tramo del 80 puede entenderse desde la necesidad de establecer un paralelismo. De hecho, Andújar Almansa en el texto seguido por Quílez, subraya estos enlaces («dentro de lo que últimamente se denomina como poesía joven, detectamos por los menos dos tramos generacionales distintos $»^{27}$ ) a la vez que atisba un reflejo del primer momento de los autores del 80:

Creo recordar que Luis Antonio de Villena vino ya a apuntar algo parecido con la poesía de los 8o. Si nos asomamos a las páginas de su pionera antología Postnovísimos (1986), comprobaremos que, independientemente de los nombres que allí figuren, la estética del realismo y el intimismo, luego dominante, constituye tan sólo una de las opciones representadas ${ }^{28}$.

Ahora que la situación de los autores del 2000 es sustancialmente distinta. Si el continuismo inicial permitió hilvanar tres sectores de tres generaciones distintas como un preludio de la hegemonía posterior ${ }^{29}$, estos jóvenes están promoviendo un cambio profundo en las relaciones tanto inter-estéticas como inter e intra-generacionales. Sin embargo, este precedente permite comprender que, en algunos casos, tras la enunciación de la diversidad lata una cierta esperanza de que alguna de las tendencias se imponga sobre las restantes. Resultan muy significativos de ello los comentarios de Manuel Rico y Ángel L. Prieto de Paula en una serie de reseñas colectivas publicadas en Babelia entre el 2002 y el 2009. El seguimiento de las mismas permite comprobar cómo el asentamiento de la diversidad en tanto que rasgo fundamental de la generación se acompaña del deseo de atisbar una o varias líneas dominantes que, metonímicamente, representen a todo el conjunto: «[estos poetas] representan, desde campos diferentes, la convivencia entre las nuevas corrientes poéticas» ${ }^{30} ;$ «En la poesía que emerge, no se percibe una estela dominante que reduzca la pluralidad creativa y la dote de unas claves homogéneas para su valoración» "; ; "El campo de la poesía más joven sigue ampliándose sin que parezca posible establecer espacios claramente acotados, corrientes dominantes o principios estéticos ampliamente com-

26 Véase nota 8.

27 José Andújar Almansa, op. cit., p. 25.

28 Ibid.

29 Miguel Casado, «Para un debate sobre la crítica de poesía», Hora de poesía, 97-I00, I996, pp. I33-I4I.

30 Manuel Rico, «Primeros pasos de nuevos poetas», Babelia, 6.7.2002, p. Io.

3 I Ángel L. Prieto de Paula, «De nuevos y no tan nuevos poetas», Babelia, I7.9.2002, p. Io. 
partidos $»^{32} ;$ «La diversidad de enfoques estéticos y la convivencia de corrientes parece haberse asentado en el panorama poético de nuestro país en esta primera década del siglo»33.

Tal y como antes anotamos, una de las consecuencias más visibles de la confusión reinante va a ser la falta de un rótulo que los aglutine y dé cuerpo al relevo generacional. Solo un reducido número de críticos propondrá en diferentes momentos un membrete que coadyuve la delimitación y permita el trazado de fronteras inter-generacionales. En este sentido, pueden resaltarse los intentos de Ana Sofía Pérez-Bustamante ${ }^{34}$ («promoción del 95») o José María Plaza ${ }^{35}$ («Generación del 2005»). Por otra parte, la dispersión a que nos venimos refiriendo explica que numerosas antologías publicadas en estos años antologuen total o parcialmente a los poetas del 2000 sin advertir que se trata de una generación nueva. Asimismo, frente a la gran cantidad de artículos y ensayos que en la década anterior permitían seguir el curso de la poesía española ${ }^{36}$, tal y como lúcidamente anota Juan Carlos Abril en 20II, pocos serán, «por no decir ninguno, los intentos de sistematizar la última oleada de nombres, estilos o libros» ${ }^{37}$.

En otro sentido, en el primer lustro de la década se produce un significativo cese en la publicación de antologías académicas ${ }^{38}$ que cronológicamente coincide con la presentación en sociedad de los nuevos autores. Desde que en el año 200I Juan Cano Ballesta publicase Poesía española reciente habrá que esperar hasta 2006, con Última poesía española (1990-2005) de Rafael Morales Barba y Con voz propia. Estudio y antología comentada de la poesía escrita por mujeres (1970-2005) de María Rosal para ver reanudado este discurso. En este contexto, resulta llamativo que los volúmenes de este tipo editados en el segundo lustro del 2000 vuelvan los ojos hacia lo anterior, posiblemente debido a la dificultad que entraña abordar la sistematización de un panorama tan heterogéneo. Así, Domingo Sánchez Mesa en Cambio de siglo (2007), Marta Sanz en Metalingüísticos y sentimentales (2007) y Ángel L. Prieto de Paula en Las moradas del verbo (2010) escoran hacia la promoción de los 70 y/o la de los 80; mientras que María Rosal en Con voz propia (2006) antologa

32 Manuel Rico, «Sin problemas de convivencia», Babelia, 3I.I.2004, p. I2.

33 Manuel Rico, «La diversidad de la poesía penúltima», Babelia, 4.4.2009, p. I3.

34 Ana Sofía Pérez-Bustamante, «Epílogo de la pluma», El placer de la escritura o nuevo retablo de Maese Pedro, Cádiz, Universidad de Cádiz, 2005, p. 280.

35 José María Plaza, «Generación 2005. Poetas de veintitantos años», Leer, I64, 2005, pp. IooI08.

36 Algunas de estas aportaciones han sido recopiladas por Juan Carlos Abril (véase nota 37).

37 En contraportada: Juan Carlos Abril (coord.), Gramáticas del fragmento. Estudios de poesía española para el siglo XXI, Granada, Asociación Cultural Cancro, 20II.

38 Nos referimos con «antologías académicas» a un tipo específico de antología nacional (general o femenina) de voluntad retrospectiva, destinada a hacer balance de las últimas décadas de poesía española. 
a algunas autoras del 2000 en el marco de una propuesta de sistematización que acaba en la década de los 90 y no contempla el cambio producido a inicios de la década siguiente. De modo que tan solo Morales Barba tratará de delinear los espacios estéticos transitados por estos jóvenes en el contexto de una antología de vocación retrospectiva ${ }^{39}$.

Todo lo expuesto hasta ahora converge literalmente en la última de las entregas de Villena: La inteligencia y el hacha (Un panorama de la Generación poética de 200o) (2010). Desde el punto de vista crítico, esta antología constituye una lúcida retrospectiva en la que Villena reflexiona sobre las complicaciones con las que se ha ido encontrando en su discurrir por el tiempo la promoción del 200o. A la vez que, desde su decidida voluntad panorámica, sistematiza las estéticas cultivadas y, por primera vez, trata de bautizarlos con un rótulo que en sí mismo condensa todas las complejidades expuestas. Así, «Generación de 2000» se refiere, en 2010, a un conjunto de autores que, en algunos casos, se dieron a conocer diez años atrás ${ }^{40}$ :

Desde hace mucho tiempo se da por hecho (implícita o explícitamente) que la última promoción vigente en la poesía española es la llamada «del 8o» -eso sí, cada vez con mayores matizaciones y distingos- pero nadie ha dado carta de naturaleza al hecho de que, desde hace ya años, existe una nueva generación (la he llamado 2000 por ser un año emblemático, y por cumplir en líneas generales la distancia cronológica que le separa de la anterior) cuyos ideales estéticos son naturalmente muy distintos a los del grupo anterior, aún teniendo en cuenta que ese grupo anterior (la «generación del 80») ha evolucionado, como entre otros he constatado yo mismo en más de una ocasión ${ }^{41}$.

39 En el terreno de las antologías de poesía reciente sobresale la aportación de Juan Carlos Abril en Deshabitados, Granada, Maillot Amarillo, 2008.

40 Con todo, Villena vuelve a conciliar en esta antología a autores del 80 y del 2000 debido, según expone, a la cercanía de los primeros con respecto a la nueva promoción.

4I Luis Antonio de Villena, «La inteligencia...», op. cit., p. Io. 